\title{
OÑA, INNOVACIÓN MONÁSTICA Y POLÍTICA EN TORNO AL AÑO MIL
}

\author{
AmANCIO ISLA FREZ \\ Universidad Rovira i Virgili
}

RESUMEN: En 1011 el conde Sancho de Castilla fundó el monasterio de Oña dentro de un ambiente de éxito tras sus victorias políticas y militares sobre los debilitados poderes de al-Andalus. Oña continúa las tradiciones de los monasterios condales, pero también se abría a nuevas influencias religiosas y culturales, con un énfasis mayor en el cuidado de los difuntos. La fundación también destacaba la voluntad de los condes castellanos de afirmar su dominio sobre los territorios septentrionales de su condado. El rey Sancho III de Navarra fue también enterrado en Oña, una decisión muy elaborada, subrayando cuán próximos estaban sus intereses y sentimientos religiosos a los de su suegro, el conde Sancho.

Palabras Clave: Monasterios funerarios. Poder condal. Manifestaciones religiosas en torno al año 1000. Castilla y Navarra hacia el año 1000.

ABSTRACT: Flushed with success in the aftermath of his political and military victories against the fading powers of al-Andalus, count Sancho of Castile founded the monastery of Oña in 1011. While Oña continued the tradition of comital monasteries, it was also open to new religious and cultural influences that placed greater emphasis on the care of the dead. The foundation of the monastery also bighlighted the desire of the Castilian counts to assert their dominion in their northern territories. King Sancho III of Navarre was buried in Oña in 1035. This was a carefully chosen decision that demonstrates how his interests and religious feelings were close to those of his father-in-law, count Sancho.

KEY WORDS: Funerary monasteries. Comital power. Religious manifestations around the year 1000. Castile and Navarre around the year 1000 . 
Los motivos legendarios de la fundación de Oña han sido relatados en varias fuentes. Jiménez de Rada y, tras él, la Primera Crónica General señalan que el conde Sancho García construyó el monasterio en memoria de su madre. La referencia se anuda a la leyenda de la condesa traidora, en la que una supuesta condesa Sancha, casada con el conde García Fernández, mataría a su esposo y trataría de que su hijo corriera la misma suerte. El nombre del monasterio, el de Oña, estaría, de acuerdo a esta leyenda, en relación con el sobrenombre de la condesa Sancha. Ambas fuentes explícitamente sugieren un elemento penitencial en la erección del cenobio ${ }^{1}$, por más que no se corresponde con el resto de la historia, en la que la condesa, una asesina de desigual éxito, muere al salir mal una de sus tretas, al ser advertido su hijo de las acechanzas maternas e insistir éste en que bebiera de la mortífera pócima que había preparado.

Nada de todo ello nos propone la Crónica Najerense, que afirma la sepultura del conde en Oña sin atribuir más motivo que el haberlo edificado ${ }^{2}$. La construcción de Oña se entiende como labor personal de Sancho García y entra dentro de los parámetros de la época que el conde hubiera decidido su enterramiento allí. Si García, el de Nájera, fue depositado en la iglesia de Santa María de la ciudad de Nájera, a la que había dedicado tanta atención a lo largo de su vida, se comprende que algo similar hubiera pasado con Sancho.

El problema sería saber por qué se desatiende Cardeña, en donde habían recibido sepultura García y Ava o, incluso, Covarrubias y Arlanza. En realidad, en la familia condal castellana no parece haberse desarrollado hasta ese momento el concepto de un panteón familiar que recogiera las diversas generaciones condales. Fernán González y sus descendientes quizá no debieron sentir la necesidad de ese reforzamiento del prestigio que suponen los enterramientos familiares, pero tampoco se vieron impulsados a hacer visible este modo de política dinástica.

El Poema de Fernán González sostiene que San Pedro de Arlanza había sido construido por el conde. En propiedad, pero siempre según la leyenda, el conde castellano habría reedificado una ermita ya erigida en el lugar ${ }^{3}$. Sus orígenes históricos, sin embargo, no están claros, pero suele admitirse una existencia

Estas páginas se redactaron el primer trimestre de 2005. No conocí la obra de Martínez Díez: El condado de Castilla (711-738), Valladolid, 2005, 2 vols., de la que el presente trabajo hubiera podido beneficiarse. El retraso en su publicación es ajeno al autor.

1 Tandem comes Sancius contriti cordis penitencia stimulatus, construxit monasterium ualde nobile quod Oniam nominanit... (De rebus Hispaniae, V, 3; ed., FernáNDEZ VALVERDE: C.C.C.M., Turnholt, 1987). El origen penitencial es un tópico, pero es posible — luego lo veremos — que haya algo de ello.

2 Sepultus apud Onie monasterium, quod fecerat (Crónica Najerense, ed., EsTÉvez SOLA: C.C.C.M., Turnholt, 1995 / ed., UBIETO, Zaragoza, 1985; III, 1 / III, 5). Sobre el primitivo enterramiento a los pies de la iglesia y los posteriores traslados Iñigo DE BARREDA: Oña y su real monasterio, según la descripción inédita del monje de Oña..., introd. y notas HERRERA ORIA, P. E.: Madrid, 1917, 28 y Olmedo Bernal, S.: Una abadía castellana en el siglo XI San Salvador de Oña (1011-1109), Madrid, 1987, p. 55 nota, remitiendo a Yepes.

3 Poema de Fernán González, 225ss (ed., Zamora Vicente, Madrid, 1970 ${ }^{4}$ ). 
previa, anterior a Fernán González ${ }^{4}$. En este monasterio sería años más tarde enterrado el conde . Conservamos algunas de sus donaciones al monasterio, por lo que cabe admitir un cierto nexo con el cenobio, aunque, dada la manipulación que han sufrido los textos, es difícil pronunciarse con mayor precisión.

Quizá podría pensarse que la particular muerte de García Fernández desarboló los planes para su enterramiento y que sus restos pudieran tener reservado otro destino, estando entre los posibles el paterno del monasterio de Arlanza. La crónica Najerense y Jiménez de Rada sostienen que su cadáver fue finalmente recuperado y sepultado en San Pedro de Cardeña ${ }^{6}$. El que su mujer, la condesa Ava, hija del conde Bernardo de Ribagorza y madre del conde Sancho, fuera enterrada también en Cardeña, nos lleva a pensar en un previo designio funerario de la pareja ${ }^{7}$. Por tanto, los condes castellanos fueron enterrados en diferentes monasterios de prestigio, con los que habían mantenido relaciones como protectores y donantes, pero ni siquiera parecen haber sido ellos los fundadores de tales cenobios.

Estos monasterios castellanos han de ser puestos en relación con la dinámica expansiva de los condes de Castilla. Covarrubias y San Pedro de Arlanza implicaban la voluntad de controlar los espacios del alto valle del Arlanza. Con las fundaciones monásticas y la tutela condal de las mismas, la familia de Fernán González generaba un núcleo subsidiario de su poder en la zona, es decir, vertebraba estos territorios y poblaciones bajo su autoridad. El que la hija del conde García Fernández, Urraca, ingresara en Covarrubias, derivando la familia condal a uno de sus miembros a la zona, es muestra de esa voluntad de ejercer su control sobre el monasterio y su entorno ${ }^{8}$.

Si las cláusulas por las que el conde otorga ciertas inmunidades al monasterio de Covarrubias son originales, se certificaría, una vez más, que no puede describirse la inmunidad como un rasgo de la debilidad creciente del poder político. Las concesiones de privilegios de este tipo, que suelen referirse a la restricción de que el sayón entre en los espacios definidos y a que no se entreguen al conde ciertas cargas, testimonian la voluntad del concedente de refor-

4 Los diplomas fundacionales, fechados ambos en el 912 —una donación de Gonzalo Téllez y su esposa y una supuesta donación de Fernán González— son falsos (ZABALZA: Colección diplomática de los condes de Castilla, Salamanca, 1998, $\mathrm{n}^{\circ} 1$ con su comentario). También, SERRANO: Cartulario de San Pedro de Arlanza, Madrid, 1925, 2 y 3.

5 De rebus Hispaniae, V, 2.

6 et corpus eius a Sarracenis redemptum in monasterio sancti Petri de Cardenia requiescit (De rebus Hispaniae, V, 18). La Najerense afirma este traslado en III, 1 / III, 4).

7 A tenor del sarcófago de inscripción transcrita por BERGANZA: Antigüedades de España, Burgos, reimp. I, $n^{\circ} 104$, p. 295: "Aqui yaze la Condesa Doña Ava, muger del Conde Garci Fernandez, y nieta del Emperador, Don Enrique". Sobre la inmunidad, IslA, A.: La Alta Edad Media. Siglos VIII-XI, Madrid, 2002, 164 ss.

8 El documento fundacional ahora en ZABALZA: Colección diplomática de los condes de Castilla, $\mathrm{n}^{\circ}$ 52, pp. 396ss. Introduce la historia de estos monasterios, ÁlvAREZ BORGE: Poder y relaciones sociales en Castilla en la Edad Media, Valladolid, 1996, 109ss. 
zar esas realidades a las que se privilegia. También a sus poderes, que podrían percibir para sí estas cargas, puesto que el sayón no habría de transferirlas al conde, pero sí al nuevo referente en la propiedad y también en la jurisdicción? El conde daba estos bienes tal y como los tenía él, por lo que, en pura lógica, no podría, a partir de entonces, extraer sus rentas y derechos. Obviamente, poderes de este cuño, como el representado por Urraca García, implicaban no un deterioro de la autoridad, sino otro modo de implementarla, una alianza directa con la condal, la asimilación plena con esa dignidad y sus prerrogativas.

Hay que destacar que en las motivaciones expresadas por los condes García Fernández y Ava en el documento del 978 sean centrales las del temor al Juicio. No es éste un caso excepcional, pero, si lo comparamos con otras escrituras de donación a centros religiosos por parte de los condes, encontramos, creo, un tono más dramático. No se trata del frecuente pro remedio animarum de la donación a Berlanga o de alguna otra. Esta cláusula está en relación con el auge de una percepción diferente de la muerte y del Juicio, cuya cronología en la monarquía leonesa es también coincidente ${ }^{10}$.

La primera relación que conservamos entre el monasterio de los Santos Cosme y Damián de Covarrubias y el conde García Fernández es, sin embargo, anterior. En el año 972 el conde había adquirido el citado monasterio de Covarrubias del abad Velasco y de los monjes, entregándoles a cambio propiedades aguas abajo del Arlanza y en el Arlanzón. Parece que este abad y comunidad monástica han de ser los de San Pedro de Berlanga, que debían tener en Covarrubias un monasterio dependiente ${ }^{11}$. En cierto modo, el conde vaciaba el monasterio para poder desarrollar su política ${ }^{12}$. En el documento del 978 aparece un abad Martín que quizá lo sea del nuevo Covarrubias y que puede ser el mismo que figura con la dignidad de abad en la escritura del 972.

Cardeña se sitúa al sureste de la ciudad de Burgos y tenemos constancia del monasterio en los primeros años del siglo $\mathrm{X}$, recibiendo donaciones de Gonzalo Téllez y su esposa, y, más tarde, nuevas concesiones serán entregadas por el conde García Fernández ${ }^{13}$.

9 Es interesante que, para referirse a los derechos y cargas percibidos, el conde prohíba que el sayón lleve lo obtenido al conde, aunque deberán servir al monasterio tal y como seruiebant ad illas sedes regales. Es evidente que estos ingresos no llegaban en puridad al rey, sino al conde, por más que se empleara la terminología regia. Los sayones que antes percibían a nombre del conde, ahora lo harían al del monasterio.

10 El texto que nos interesa: ... extremitate ultimi iudicii diem enix (ius\} decernentes, expedit ducatum mentibus nostris aliqu(i)d preponere, quatenus cum tuba terribilis mundum concusserit omne iubamine a culpe in Christo mereamur accipere. La cronología es coincidente con lo que hemos señalado en Memoria, culto y monarquía. El documento de donación a Berlanga de 975 en ZABALZA, n ${ }^{\circ} 51$.

11 Vid., la referencia de Serrano para el nexo de Covarrubias con Berlanga, p. 4. Las propiedades que recibe el abad a cambio se encuentran en las proximidades del monasterio madre.

12 ZabalZa, no 48; Serrano, $\mathrm{n}^{\circ} 2$.

13 Moreta: El monasterio de San Pedro de Cardeña. Historia de un dominio monástico castellano (902-1338), Salamanca, 1971, 39ss. 
Oña, en cambio, está en tierras de la Bureba, en una vía que el río Oca abre hacia el Ebro, en donde desemboca un par de kilómetros después para dirigirse a Traspaderne, a unos diez kilómetros del monasterio. Es, por tanto, una ruta que tiende a los espacios alaveses y, siguiendo el curso del Ebro, riojanos. Es también una zona fértil, quizá más si la comparamos con su entorno montañoso $^{14}$, pero las dimensiones para la expansión agraria son limitadas, aunque es factible el aprovechamiento ganadero de los bosques circundantes.

Parte del interés del valle del Oca se deriva de ser una vía de comunicación. En alguna ocasión la recorrieron los ejércitos andalusíes y nos consta que una campaña de Abd al-Rahman III en el año 934 llegó hasta la zona y la asoló. Las noticias, transmitidas por el Muqtabis, presentan un ejército andalusí que avanzó de este a oeste. La momentánea paz que estableció con la reina Toda llevó a Abd al-Rahman III contra tierras castellanas, iniciando su campaña con el ataque a Grañón, el primer enclave castellano. Es decir, el califa salió desde su campamento en Calahorra y siguió la ruta de la antigua vía romana de Zaragoza a Astorga, pasando por Tricio hacia Briviesca. La campaña consistió, como tantas veces, en una sistemática destrucción del territorio, lo que implica desviaciones del sentido de la marcha en todas direcciones con devastaciones generalizadas sobre viviendas y tierras de labor. Así se explica su movimiento hacia Oña con la pretensión de destruir su fortaleza, pero también para aniquilar un rico monasterio. Es posible que sus exploradores o, quizá, los guías navarros que es presumible que acompañaran al califa, le dieran noticia de la existencia de este rico paraje. Tras proceder a lo que parece una exitosa operación, el ejército andalusí pasó por Burgos, es decir, siguió el recorrido de la vía romana del Arlanzón hasta Simancas, y luego se dirigió hacia el este, a Clunia ${ }^{15}$.

El monasterio atacado en el 934 estaba en el entorno de Oña y era conocido por este nombre ${ }^{16}$. No sabemos si la edificación se recompuso y si el monasterio actual está levantado sobre sus ruinas. Es muy probable, puesto que su riqueza en materiales haría factible una pronta reparación y cierta recuperación de la comunidad $^{17}$. Se entendería así también la "fundación» condal de 1011, procediendo sobre una base ya existente que se pudo magnificar, en la línea que hemos visto para Covarrubias y quizá en la misma estela que otras inauguraciones.

14 Del Álamo recoge alguna noticia sobre la feracidad de la zona (Colección diplomática de San Salvador de Oña, Madrid, 1950, I, pp. XXVIIs).

15 Hay que recordar el trabajo de SÁNCHEZ AlbORNOZ: «De Birovesca a Suessatio», publicado originalmente en 1931 y luego en Orígenes de la nación española, I, Oviedo, 1972, 129ss.

16 Lo confirma el parte de la victoria, que menciona «la fortaleza de Oña, su llano y monasterio de su nombre» (IBN HAYYAN: Crónica del califa Abdarrabman III An-Nasir entre los años 912 y 942 (al-Muqtabis V), ed., Viguera, M.J. y CorRIENTE, F., Zaragoza, 1981, p. 257).

17 El texto del Muqtabis sostiene que estaba «completamente rodeado de colinas que ocultaban su dilatada superficie donde se alzaban elevados edificios de altas columnas, maravilloso mármol y admirable fábrica, mientras entre casas y palacios estaban asignados a distintos fines y trazados para distintas utilidades, reuniendo allí cuantas actividades necesitaba la gente...» (ed., VIGUERA Y CORRIENTE, p. 254). 
Desde los últimos años del siglo $\mathrm{X}$ parece desarrollarse una actividad expansiva por parte del conde castellano. Pérez de Urbel había advertido que durante este período las escrituras del monasterio de San Millán se calendaron haciendo referencia al poder castellano y no por el monarca navarro ${ }^{18}$. Con todo, la mayoría de estos documentos se refiere a donaciones a cenobios castellanos que sólo más tarde recaerían en San Millán, por lo que era muy normal que no se mencionara al rey navarro ${ }^{19}$. Sin embargo, hay algún testimonio del interés condal por el monasterio, una donación del propio conde Sancho y su hermana del año $1003^{20}$, que puede señalar un intento de aumentar su influencia en la zona, quizá en un momento en que García Sánchez II estaba enfermo. Poco después ya se destaca en las escrituras emilianenses el reinado de Sancho III y no vuelve a haber donaciones al monasterio de los condes castellanos.

El año 1009 supuso un notable cambio en la frontera y, en general, en el equilibrio de poderes. Los beréberes, acuciados por múltiples dificultades, solicitaron la ayuda del conde Sancho mientras ponían sitio a Medinaceli. La posición de Sancho era óptima para negociar, pues también la otra facción musulmana en liza reclamaba su ayuda y le enviaba embajadores ${ }^{21}$.

Sancho envió cuantiosos suministros a los beréberes quienes, a cambio, se comprometieron a entregarle las plazas del Duero. Es admisible que las referencias transmitidas por Ibn Idhari no sean exactas 22 , pero, por poco que se

18 PÉreZ de Urbel: Historia del condado de Castilla, Madrid, 1945, II, 881s.

19 Así el documento $n^{\circ} 115$ fechado en 998, en el que figura el conde Sancho y Asur Núñez como dominante en Pancorbo, pero es una donación a San Felices de Oca. También lo son el de $1004\left(\mathrm{n}^{\circ}\right.$ 126) y el de $1007\left(\mathrm{n}^{\circ} 130\right)$. El $\mathrm{n}^{\circ} 121$ de 1001 es una donación de propiedades en Atapuerca a San Juan de Hiniestra. También lo son los de 1005 ( $\mathrm{n}^{\mathrm{o}} 127$ y 128). El $\mathrm{n}^{\circ} 129$ se dirige a un monasterio femenino innominado. Otras remiten al monasterio de San Mamés de Obarenes ( ${ }^{\circ}$ 134 y 137) (Ubieto Arteta, A.: Cartulario de San Millán de la Cogolla, (759-1076), Valencia, 1976). Sobre esta agregación de monasterios culminada en época de García el de Nájera, vid., GARCÍA DE CORTÁZAR: «Monasterios hispanos en torno al año mil», en Ante el milenario del reinado de Sancho el Mayor, XXX a semana de Estella, Pamplona, 2004, $236 \mathrm{~s}$.

20 San Millán, $\mathrm{n}^{\circ}$ 123; ZabalZA, $\mathrm{n}^{\circ}$ 62. La carta es confirmada por Fernando Vélaz, Oveco Álvarez, Vela Álvarez y el senior Asur Núñez, dominante en Pancorbo, entre otros. Comenta los documentos de Sancho, MARTíNEZ DíEZ: «El monasterio de San Millán y sus monasterios filiales. Documentación emilianense y diplomas apócrifos» en Brocar, 21 (1997) 41s. Sobre la competencia por San Millán en esos años, vid., GARCía DE CORTÁzAR: El dominio del monasterio de San Millán de la Cogolla, Salamanca, 1969, 139ss; matiza ZABALZA, 451ss.

Hay una concesión del monasterio del Taranco (Mena) al de San Millán realizada por el conde Fernando Ermegíldez y su hermano que cita al rey navarro y al conde castellano, aunque el resto de los personajes procede del entorno navarro (San Millán, no 131). El personaje Fernando Ermegíldez puede ser el mismo que aparece en el fuero de Brañosera. El documento me parece sospechoso.

21 IBN IDARI: La caída del Califato de Córdoba y los Reyes de Taifas (al Bayan al-Mugrib), ed., MaílLo SALGADO, Salamanca, 1993, 82.

22 El conde Sancho «enseguida envió a los beréberes mil carros de harina, de especias y [diversas] clases de víveres, mil bueyes, cinco mil ovejas y todo lo que les convenía, hasta carbón y miel, sillas para montar, telas para vestirse y otras cosas, además de cuerdas y estacas para las tien- 
aproximen, mostrarían cuáles eran las disponibilidades económicas de los cristianos. En efecto, si, sin mediar tiempo de preparación, el conde Sancho podía suministrar una notable cantidad de recursos y, más aún, establecer un sistema para hacerlos llegar a Medinaceli, hay que admitir que su condición no podía ser de extrema penuria, como resultado de las razias amiríes. La noticia no debe ser completamente errónea, puesto que, si los cristianos hubieran vivido en la pobreza o los beréberes no hubieran recibido considerable impedimenta, ni habrían sido remitidos los socorros ni habrían mantenido el cerco a la ciudad, algo que Ibn Idhari no podría silenciar. De manera que, como hemos señalado en alguna otra ocasión ${ }^{23}$, no cabe sostener que los cristianos habían sido reducidos a la casi inanición por los ataques amiríes de los años anteriores.

Además, Sancho García dirigió un ejército que se encaminó a Medinaceli. Parece haber habido una propuesta de negociación por parte del conde castellano a los sitiados. Tales intentos pretenderían reducir las pérdidas propias y asegurarse la condición de árbitro de la discordia intramusulmana con las consiguientes ventajas políticas y económicas.

La derrota cerca de Alcalá de Henares de las fuerzas de Wadih, el jefe de la Marca Media, y la de los cordobeses en las proximidades de Córdoba posibilitaron la llegada al poder de Sulayman al-Mustain y los beréberes. También supuso la victoria de los castellanos. La nueva autoridad no pudo entregar a Sancho las fortalezas que había solicitado, puesto que aún no estaban en su poder sino en el de Wadih, pero hemos de pensar que compensaría sobradamente a las tropas que lo habían colocado en el califato.

Los equilibrios políticos cambiaron en Córdoba con la vuelta al poder de Hišam II y la designación de Wadih como haŷib, aunque el conflicto distaba mucho de haberse calmado. A fines del 1010 el conde castellano presionó a los cordobeses y consiguió las plazas del Duero tomadas por los ejércitos andalusíes desde época de al-Hakam II. Los analistas castellanos señalan que el conde recibió las de Clunia, San Esteban y Gormaz. Además, otros enclaves, entre ellos Berlanga, Meconia y Castrabón ${ }^{24}$. Berlanga es Berlanga de Duero, a una docena de kilómetros al este de Gormaz, pero merece la pena detenerse en ubicar los otros topónimos.

Castrabón era un lugar fortificado de cierta envergadura que aparece en alguna otra ocasión en las fuentes árabes. En concreto, en la campaña de Abd alRahman III del 939 que terminó con el desastre de Simancas-Alhándega. El ejército califal que con al-Nasir escapó de la batalla se dirigió hacia el este, pues su destino final sería Guadalajara y se protegió por un tiempo en la fortaleza de

\footnotetext{
das. Vivieron con esto los beréberes y se fortalecieron» (IBN IDARI, ed. Maíllo, 82).

23 IsLA, A.: «Warfare and Other Plagues in the Iberian Peninsula around the Year 1000», en Europe around the Year 1000, ed., P. Urbanczyk, Varsovia, 2002, 233 ss.

24 Era MLXI. Dederunt Comiti (Sancio) Sanctum Stephanum, E Cluniam, E Osmam, E Gormaz, E dederunt ei quinquaginta obsides pro Castrabo, E Meconia, E Berlanga (Chronicon Burgense, en FLóREZ: España Sagrada, XXIII, 307ss). Las exigencias cristianas en IBN IDARI, pp. 95 y 96.
} 
Qstrb. La dirección del viaje del ejército derrotado nos lleva hacia el este y una noticia, referida a otra expedición de Abd al-Rahman III, la sitúa en las proximidades de Gormaz ${ }^{25}$. Con todo, su ubicación exacta eludió a los historiadores $^{26}$. La citada retirada, tras el desastre de Simancas, hubo de pasar por la zona de Riaza, puesto que los de Guadalajara insistieron en que se realizaran por la comarca acciones militares. Martínez Díez dio noticia de un documento de mediados del XII, procedente del obispado de Sigüenza, que colocaba a Castrobón en el entorno de Caracena y quizá en Castrón debió encontrarse ese punto fortificado ${ }^{27}$.

El otro enclave aparece en las fuentes árabes como Mituniya. En los textos latinos, puesto que es citado en Sampiro resaltando una derrota de Ordoño II, figura como Mindonia, Mitonia, Mictonia o Mudonia ${ }^{28}$. Hacia él se dirigió una campaña en el 918 en la que un ejército andalusí saqueó la zona. El Muqtabis no proporciona ningún otro elemento geográfico, por lo que es difícil localizarlo. Pérez de Urbel ubicó el topónimo en una oscura Miconia, «al sur del Duero» o, con más frecuencia, en Monzón de $\mathrm{Campos}^{29}$. Me parece más verosímil pensar en Modamio, lugar en el valle que recorre el arroyo de la Fuente y que vigila una vía de comunicación que conduce a Gormaz, situado unos catorce kilómetros al norte.

Es decir, Sancho García recuperó las plazas fuertes del Duero, una serie de enclaves fortificados cuyo eje era San Esteban-Gormaz y en el que las fortalezas al sur del Duero servían para completar sus capacidades estratégicas. Dos cortaban las rutas meridionales próximas a los ríos Caracena y de la Fuente y Berlanga cerraba las vías desde el sureste. Así quedaba protegida la línea defensiva del Duero, reforzada probablemente con otros bastiones menores ${ }^{30}$.

25 La expedición del 934 acampó junto a Gormaz, a diez millas de Ayllón, y a la siguiente jornada se estableció en Qstrb, a cinco millas de Gormaz. Las distancias no parecen muy precisas (vid., Muqtabis V, p. 256).

26 ChalmetA, P.: «Simancas y Alhándega», en Hispania (Madrid) XXXVI (1976) intentó ubicarla «entre la cuenca del río Asa y Atienza» (p. 427s) y en cualquier caso «en la cuenca del río de Tielmes» (p. 432), aunque propuso diversas posibilidades.

27 MartíneZ DíEZ: «La campaña de Simancas del año 939, Castrobón y el Barranco: ubicación exacta», en C.H.E., LV-LVI (1981), 25ss. Agradezco a Eduardo Manzano esta referencia.

28 LÉvi ProvençAL: España musulmana, IV, Madrid, 1957, 281 y n $^{\mathrm{a}}$ 50. Muqtabis, V, ed. Viguera y Corriente, p. 117, $\mathrm{n}^{\mathrm{a}}$ 1. PÉREZ DE URBEL: Sampiro, su crónica y la monarquía leonesa en el siglo X, Madrid, 1952, p. 313; la Historia de rebus Hispaniae de Jiménez de Rada se refiere a Mindonia (ed. FernándeZ VAlverde, IIII, xxiii, 4).

29 España cristiana, $112 \mathrm{y} \mathrm{n}^{\mathrm{a}} 11$. Pérez de Urbel destaca entonces que el lugar de la campaña del 918 debía relacionarse con la plaza entregada a Sancho García. Ya hemos visto que lo apuntaba Lévi-Provençal. En Sampiro, su crónica y la monarquía leonesa en el siglo X, p. 380s lo identifica con Monzón, del mismo modo que había hecho en Historia del condado de Castilla.

30 Quizá formaba parte de este diseño estratégico Maderuelo, incluido por Jiménez de Rada en la lista de plazas entregadas: Hic optinuit Pennam Fidelem et Septempublicam et Matrolium et Montelionem et Gormacium, Oxomam et Sanctum Stephanum, que in captione patris perdiderant Christiano (V, iii, 3ss). 
La exigencia de Sancho García a los beréberes debió preocupar al rey navarro. Ibn Idhari señala que Sancho III realizó una maniobra en el mismo sentido, aprovechando la situación de debilidad de los contendientes por el califato. Es evidente que el rey Sancho se movía para evitar quedar desbordado por el conde castellano. Por otra parte, ambos poderes compartían una visión estratégica de la frontera ligada a las prácticas militares que habían sido decisivas a lo largo del siglo $\mathrm{X}$.

Es éste un período de gran exaltación. La eliminación de la amenaza amirí, la entrega - eso suponemos - de numerario y la recuperación de las plazas remiten a una nueva época que se abría en el condado castellano. Dentro del reino leonés, el conde Menendo González había muerto en 1008 y la autoridad del conde Sancho se hacía notar ante el joven Alfonso V.

Desde el inicio de su reinado, la actuación de Sancho III de Navarra se dirigió a los márgenes de su reino. Hacia el este se encontraba con áreas en litigio con Castilla. Estos problemas provocaron una aceptación de fronteras que se plasma en un pacto de 1016. El acuerdo está directamente relacionado con la expansión hacia el sur, propiciada por la entrega de fortalezas que ya hemos mencionado, y cabe pensar que entre 1010 y la fecha de la concordia se produjeron algunas dificultades. Por otro lado, esos convenios no afectaron al límite norte del área castellana, quizá mostrando lo espinoso de resolver esa línea ${ }^{31}$.

En una fecha difícil de precisar ${ }^{32}$, Guillermo, hijo del conde Isarno, ocupó el condado de Ribagorza tras un período de dificultades en el que se habían combinado ataques musulmanes y problemas sucesorios. A la muerte sin descendencia de sus hermanos varones, Toda reclamó la presencia de su sobrino Guillermo, hijo de Isarno ${ }^{33}$. La Crónica de Alaó nos informa de que el personaje, que era hijo extramarital del conde Isarno, se encontraba en la corte de Sancho de Castilla. Esta presencia de Guillermo Isarno en el entorno castellano se debe a ser Ava de Ribagorza, la hermana de su padre, esposa de García Fernández, es decir, se hallaba acogido en la corte de su primo el conde Sancho ${ }^{34}$. En su

31 San Millán, no 166. GARCíA DE CORTÁzAR (El dominio del monasterio de San Millán de la Cogolla, Salamanca, 1969, 141), recogiendo la opinión de Ubieto, admite cierta conflictividad subyacente en los acuerdos.

32 Para Pérez de Urbel, en torno al 990 (Sancho el Mayor de Navarra, Madrid, 1950, 41), pero quizá es fecha muy temprana. Sobre Guillermo Isarno vid., D'ABADAL, R.: «Origen i procès de consolidació de la seu ribagorçana de Roda», en Dels visigots als catalans, II, Barcelona, 1986 ${ }^{3}, 85$ ss (se publicó primero en castellano en E.E.M.C.A., V, Zaragoza, 1952, 7-82). Data la inauguración de su poder hacia el 1011, en función de la muerte del conde Suñer de Pallars que, según la crónica de Alaó, desencadenaría la arribada de Guillermo.

33 Durán Gudiol: Los condados de Aragón y Sobrarbe, Zaragoza, 1988, 273, duda que la condesa Toda casara con su pariente el conde Suñer de Pallars, a pesar de que lo afirma la crónica. R. d'Abadal sostiene que, una vez viuda en el 1011, Toda reclamaría a su sobrino.

${ }_{4}$ Toda... missit ad Castellam per nepotem suum nomine Guillelmum Isarni, quem genuerat Ysarnus prefatus ex concubina, qui erat in curia regis Sancii avunculi sui (D'ABADAL: Catalunya carolingia III, Els comtats de Pallars i Ribagorça, I, Barcelona, 1955, 20). 
marcha a Ribagorza, Guillermo fue acompañado por un ejército castellano que venció a los musulmanes y aseguró su control sobre el territorio.

Un complejo problema es el de la datación de estos sucesos. En un documento de Obarra que lleva la fecha de 1009 se afirma que es regnante super nos Gillermo comite filio Ysarno ${ }^{35}$. El documento está redactado por el presbítero Mirón que lleva a cabo otras escrituras por esos años. Algo más tarde el propio conde Guillermo realizaba un donativo al mismo monasterio, señalando que ese agosto era el segundo año del conde Guillermo en Ribagorza ${ }^{36}$. El conde haría otra concesión a Obarra en fecha difícil de establecer ${ }^{37}$. Si atendemos, pues, a las datas de los documentos, es posible que Guillermo actuara ya en el condado años antes de la muerte de Suñer de Pallars en $1011^{38}$, lo que tampoco sería extraño dada la tradición de compartir el condado. Sin embargo, si consideramos como elemento desencadenante la fecha de la muerte de Suñer, hemos de posponer estos acontecimientos hasta el 1011 y resumir en seis años la expulsión de los musulmanes, el afianzamiento de su poder y el conflicto con los araneses.

En cualquier caso, es evidente que la presencia pirenaica del nuevo conde pasaba por la aquiescencia castellana. Esta actuación creo que habría de estar destinada a controlar cualquier expansionismo pirenaico de Sancho III ${ }^{39}$. Es probable que su muerte tuviera lugar en 1017, pues la crónica de Alaó señala que fue muerto por los araneses y en el año 1018 ya encontramos documentos que se calendan por el rey navarro ${ }^{40}$.

35 Martín DuQue: Colección diplomática de Obarra (siglos XI-XII), Zaragoza, 1965, no 12.

36 La carta está dada un seis de agosto de un año que sólo se establece por ser el segundo de Guillermo, fecha que el editor apunta entre 1010 y 1012 (Obarra, $\left.\mathrm{n}^{\circ} 19\right)$.

37 La escritura trae la siguiente datación: Facta charta helemosinaria in mense yulio, anno millesimo tercio, regnante Rocberto regem (Obarra, $\mathrm{n}^{\circ} 20$ ). Martín Duque propone el olvido de una X o del término decimo, es decir, el año 1013, puesto que el año 1003 no parece posible.

38 Lo sostiene Durán, para quien Guillermo combatiría al conde Suñer de Pallars (p. 274s). Es posible el conflicto: sabemos que el conde Suñer o desgajó del obispado ribagorzano algún territorio en provecho de Urgell o lo sometió al urgelitano, aprovechando la situación depauperada del obispo Aimerico, quien había sido raptado por los musulmanes en su sede de Roda, viéndose forzado a empeñar sus recursos («Origen», 83s). Quizá se hacía muy evidente una voluntad de absorción.

No olvidemos que la Crónica de Alaó yerra en otros extremos: otorga al conde Sancho el título de rey y afirma que era tío de Guillermo.

39 Se entendería también así —insistiremos luego — la negociación de Sancho de Castilla con el conde de Barcelona Ramón Borrell para casar a los hijos de ambos, acuerdos matrimoniales propiciados por Mundir de Zaragoza. La política de Mundir de amistad con el condado de Barcelona y sus nexos con el conde Sancho en IBN IDARI: La caída del Califato, p. 152.

40 Durán arguyó un documento, fechado en 1011, en que Mayor, con el título de condesa, realizaba una donación a su fidelis Enardo (Obarra, $\left.\mathrm{n}^{\circ} 15\right)$. Debe tratarse de la condesa Mayor, esposa del conde Ramón Suñer de Pallars, repudiada por parentesco también en un momento impreciso. No debe confundirse a esta Mayor con la reina navarra. La crónica de Alaó dice que, viuda de Sancho, casó con Ponce de Tolosa, lo que es a todas luces una confusión (LACARRA: «Textos navarros del códice de Roda», en E.E.M.C.A. (Zaragoza) I (1945), tirada aparte, pp. 28s, n² 28). 
No sabemos cuándo tuvo lugar el matrimonio de Sancho con la hija primogénita del conde castellano. Es probable que se celebrara, como quiere Pérez de Urbel, en el año $1010^{41}$. El matrimonio pudo estar diseñado para solventar conflictos de todo tipo, tanto los fronterizos hacia el Duero — dada la evolución del califato y la frontera- como quizá en el Pirineo, si los acontecimientos que instauran a Guillermo Isarno son anteriores.

Solemos contemplar este matrimonio desde la óptica de Sancho III, como preludio de su herencia del condado castellano, es decir, como un eslabón más en la política expansiva del Mayor. Sin embargo, esta aproximación no es plenamente válida y habría que atender lo que implicaba esa unión desde la perspectiva del conde Sancho, con un heredero varón recién nacido ${ }^{42}$ y una hermana como reina madre en León, fortaleciendo su posición en el conjunto peninsular mediante nuevas alianzas.

Esta política matrimonial continúa mostrando la voluntad de aumento de influencia y, al tiempo, el prestigio del conde. En 1016 Sancho García preparaba el matrimonio de su hija Sancha con uno de los hijos del conde Ramón Borrell de Barcelona. El proyecto matrimonial transmite la apertura del conde castellano a diferentes ámbitos. Podemos adivinar que los vínculos a establecer revelaban su atención hacia los territorios orientales y cabe deducir que las dificultades del conde de Castilla con Sancho de Navarra no habían desaparecido por completo. Las negociaciones matrimoniales tuvieron lugar en tierras de Zaragoza, bajo el amparo de Mundir, dejando en evidencia a los distintos poderes que vigilaban el expansionismo de Sancho III y que estaban interesados en promocionar políticas que lo limitaran ${ }^{43}$.

Es en el contexto de exaltación de una época — con la expedición andalusí, la recuperación de las plazas y el nacimiento de un heredero varón- cuando el conde Sancho funda Oña ${ }^{44}$. Puede sorprender su localización en relación con los grandes cenobios castellanos de Cardeña, Arlanza y Covarrubias. Ya hemos referido que se encuentra en este eje de comunicación con las tierras más septentrionales. Obviamente, la gran fundación y la disposición al frente del monasterio de su hija Tegridia pone de relieve el interés de la familia condal por estos espacios y la afirmación de su dominio sobre ellos ${ }^{45}$.

41 Sancho el Mayor, 32. La primera mención de Mayor como reina es un documento emilianense del 24 de junio de 1011 (San Millán, no 142).

42 García, el hijo del conde Sancho debió nacer a fines de 1009, puesto que el Chronicon Burgense señala que fue el mismo año de la campaña de Córdoba. Es posible que este heredero varón es el que abriera la posibilidad al matrimonio de su primogénita con el rey navarro.

43 Dozy, R.: Recherches sur l'bistoire et la littérature de l'Espagne pendant le Moyen Âge, Leyden, 1881, I, 203ss.

44 El P. Serrano destacaba la erección del monasterio como un acto de gracias a Dios (SERrano, L.: El obispado de Burgos y la Castilla primitiva, Madrid, 1935. I, p. 198). El documento fundacional en ZABALZA, no 64, preferible a Del ÁlAMO no 8.

45 Este alejamiento de Oña de los parajes monásticos más habituales es posible que no sólo responda a la decisión política del conde de consolidar su autoridad en estos territorios. Cabe pensar 
El monasterio se coloca bajo la advocación del Salvador, Santa María y San Miguel. No es nada peculiar, al contrario resulta enormemente tradicional, pues son muy numerosos los cenobios dedicados al Salvador en el reino leonés a lo largo del siglo X. Si, además, el monasterio continuaba otro anterior -el afectado por la algara de Abd al-Rahman III- no habría de extrañar esa advocación. Con todo, quizá no sea tan frecuente en el siglo XI, en el que aparecen nuevas devociones y se erigen monasterios e iglesias dedicados a santos como Isidoro, el de Sevilla o el de Chios, Antolín o Lorenzo.

García de Cortázar - a partir de una sugerencia de Landes - ha destacado la carga devocional nueva (apocalíptica) de tal titulación en relación con su fundación en las proximidades del año mil ${ }^{46}$. Ciertamente, algunos monasterios recibieron una denominación de este tipo como San Salvador del Monte Tabor, fundado en época de Odón de Cluny. Aquí creo que nos encontramos dentro de una percepción soteriológica nada extraña a las propias enseñanzas cluniacenses. Es esta concepción del Dios crucificado, misericordioso y salvador la que está presente en las nuevas denominaciones de principios del siglo XI, entre ellas Oña y Cornellana.

El documento de fundación de Oña destaca en su exposición religiosa el papel salvador del Hijo. El Hijo de Dios se hizo carne para la redemptio del género humano y así padeció y murió. La fundación monástica se justifica $o b r e-$ medium nostrarum animarum. Añaden los otorgantes que en el último día desean que per horum preces ac suffragia puedan salir ilesos del terrible juicio final. Obviamente, esperan que esas preces y sufragios procedan de la comunidad monástica que han fundado bajo la advocación del Salvador. Estamos, pues, ante una evolución, que ya hemos señalado ${ }^{47}$, que resalta la función de las comunidades monásticas como focos de oración por el alma de los donantes.

El sentido del Dios hecho hombre es reforzado por la advocación de María, que, por otra parte, también tiene una tradicional relación con los difuntos. Como ya hemos señalado en alguna otra ocasión, San Miguel era considerado un patrono tutor de las almas de los difuntos ${ }^{48}$. Que esta tríada de titulares proteja el monasterio de Oña, en donde quieren ser enterrados los condes de Castilla, se nos antoja plenamente adecuada con el destino del cenobio. El conjunto cobraba así un sentido salvífico y protector.

Creo que puede afirmarse una influencia de la Regla benedictina sobre el documento fundacional de Oña. La temprana benedictinización de tierras cas-

que desde la perspectiva religiosa se subrayara la voluntad de distanciamiento monástico, quizá en conexión con tendencias más ascéticas que se están manifestando en todo Occidente.

46 «Monasterios hispanos en torno al año mil», en Ante el milenario del reinado de Sancho el Mayor, XXX ${ }^{\mathrm{a}}$ semana de Estella, Pamplona, 2004, 244. El trabajo de LANDES: «The Fear of an Apocalyptic Year 1000: Augustinian Historiography, Medieval and Modern», en Speculum, 75 (2000) 144.

47 Memoria, culto y monarquía Hispánica entre los siglos X y XII, Jaén, 2007, cap. II.

48 Memoria, culto y monarquía, cap. II. 
tellanas con respecto a zonas más occidentales de la Península ya fue advertida por Bishko y estudiada por Linage ${ }^{49}$. Lo que hallamos en el diploma oniense es un verdadero pronunciamiento en esta línea. Este influjo es formal, pero de ello podemos deducir una impronta quizá más relevante que la mera aparición en una escritura de una rotunda afirmación de seguir la regula. El texto de la regla benedictina se inicia con un Obsculta, o fili, destacando una comunicación directa con quien la atiende (el que la escucha); y en el texto oniense los padres se refieren a Tegridia con un tua sit o Filia... con un estilo directo muy particular que parece contagiado por la misma. Por otro lado, al referirse a la condición abacial en que Sancho y su esposa Urraca colocan a Tegridia emplean el verbo elegimus eam ut preeset, es decir, la designaron para dirigir la comunidad, mientras que la regla benedictina se refiere al abbas qui praeesse... (II). No son muchos elementos, pero, ciertamente, constituyen una muestra relevante, dado el escaso volumen dispositivo de la carta fundacional oniense.

Una comparación entre el texto fundacional de Covarrubias y el de Oña, separados por una treintena de años, muestra algunas de las transformaciones que se han venido operando. En el texto oniense, una invocación trinitaria desarrollada recalca la encarnación y la redención operada por la muerte de Cristo. La redención no queda al margen de las preocupaciones en Covarrubias. Allí se señala que quien contravenga las disposiciones tendrá parte con Judas y no cum Christo Redemptore. En ambos textos encontramos referencias al juicio final y a la necesidad del perdón de los pecados. También en los dos, los condes presentan a sus hijas como ofrenda, como munus. El paralelismo de los textos nos remite a alguna fórmula de oblación: decreuimus munus offerre Domino Ihesu Christo en Covarrubias y decreuimus eciam Domino Ihesu Christo creatori omnium, oferre in munere filiam... en la escritura de Oña.

En definitiva, se trata de textos parejos, aunque en el de Oña se ha elegido una fórmula que subraya la redención operada por Cristo. Desde luego una fórmula tradicional, como apunta el editor, pero que quizá se acomodaba a esta percepción del Cristo más humanizado y próximo al ser humano propio del año mil. Además, en Oña aparecen unos contenidos que no están en Covarrubias, en función de que los condes García Fernández y Ava no establecían este monasterio como su espacio funerario. En el texto oniense se hace explícita la voluntad de los condes de erigir un panteón. Los condes Sancho y Urraca realizan la traditio de sus cuerpos y almas, sin que ello implique la entrada física en la comunidad, pero con los nexos espirituales y con todo el contenido que ello tiene en cuanto al lugar de sepultura. Además, hacen referencia a que esta limosna sirva para la salvación de sus almas y las de sus parientes, tanto los ya difuntos como los que todavía no han nacido. Hay, pues, un elemento de continuidad dinástica

49 BISHKO: «Salvus of Albelda and Frontier Monasticism in Tenth-Century Navarre», en Studies in Medieval Frontier History, Londres, 1980, cap. I. Sobre la benedictinización, LINAGE: Los orígenes del monacato benedictino en la Península Ibérica, León, 1973, II. 
que confirma el deseo de diseñar un panteón familiar. En Oña, pues, se combinaba la tradición de los «infantados» para las mujeres de la familia condal ${ }^{50}$ con la creación de un panteón que recibiera los restos de los condes y sus descendientes, una voluntad de continuidad dinástica que se manifestaba poco después del nacimiento de su heredero.

Puede extrañar la fecha de la redacción de la carta o, más bien, su forma de expresarla. Se data iniciando la cuaresma del 1011 en la segunda feria ${ }^{51}$, es decir, puesto que la pascua ese año fue el 25 de marzo, se trataría del lunes 12 de febrero. Es una fórmula de datación nada corriente que viene a subrayar el momento del año litúrgico en que se consagra Oña, fecha a la que se quiere dar realce y poner en estrecha vinculación con la fundación monástica.

Lo presumible es que el documento se elaborara en el mismo monasterio, al que habrían acudido los condes y su séquito para las solemnidades del domingo e, incluso, donde quizá podrían haber llegado para el miércoles de ceniza, el día 7 de febrero, produciéndose la consagración solemne del templo el domingo, como imponía la tradición canónica ${ }^{52}$. El lunes, el mismo día de inicio de la Cuaresma en la liturgia hispánica, estamparían su signo en el documento, acompañados de los obispos que habrían realizado la liturgia del día anterior. La liturgia de la cuaresma incidía en la solicitud de la misericordia divina dentro del espíritu penitencial del momento y, así, se reforzaba la solicitud de la remissio peccatorum. Hay en la liturgia cuaresmal una insistencia en la regeneración, hecha posible por la miseratio divina y el sacrificio de la Cruz, por tanto se recalcaba el papel de Cristo como Salvador y en el hombre regenerado como un novus homo. La liturgia destacaba la necesidad de abrir un tiempo nuevo en el que los hombres se sometieran a los mandatos divinos, volviendo a un momento originario ${ }^{53}$. Todos estos elementos se componían con la voluntad de erigir un monasterio, también símbolo de una renovación, que iba a acoger los despojos de la familia condal.

No convendría desconsiderar que entre estas fechas se encuentra el 10 de febrero, es decir, ese sábado se conmemoraba a Escolástica, la hermana de Benito de Nursia y referente monástico femenino por antonomasia. Su festividad no aparece en los calendarios mozárabes, pero sí entre los romanos y su existencia era de sobras conocida gracias a las líneas que le dedicara Gregorio Magno ${ }^{54}$. La proxi-

$50 \mathrm{Ha}$ escrito sobre el infantado, Henriet, P.: «Deo votas. L'Infantado et la fonction des infantes dans la Castille et le Léon des $\mathrm{X}^{\mathrm{e}}$-XII ${ }^{\mathrm{e}}$ siècles», en Henriet, P. y LegraS, A.-M.: Au cloître et dans le monde. Femmes, hommes et sociétés (IX ${ }^{e}-X V^{e}$ siècle), París, 2000, 189-203.

51 Del Álamo da alguna explicación sobre la data (Colección diplomática de San Salvador de Oña, p. 11, nota).

52 III concilio de Zaragoza del 691, c. 1; VIVES, J., ed.: Concilios visigodos e hispanos-romanos, Barcelona-Madrid, 1963.

53 Breviarium, PL, LXXXVI, 267C. El fiel solicita que cese la ira de Dios y que se establezca la paz (ibid, 261).

54 Dial., II, 33 y 34. 
midad de tal fecha ayudaría a explicar más adecuadamente la elección de aquellos días para inaugurar una fundación que iba a ser encabezada por una mujer y que tenía un alto contenido funerario ${ }^{55}$. Si esto es así, tendríamos un elemento más que apuntaría al desarrollo de la influencia benedictina en tierras castellanas. Otro asunto es si el monasterio de Oña seguía la norma benedictina. La referencia a Dei cultores y omnes Deo deuotas, a los famuli y famulae, parece apuntar a un monasterio dúplice, lo que haría improbable el seguimiento de la regla en un sentido pleno.

El 5 de febrero de 1017 moría el conde Sancho y, de acuerdo a su voluntad, fue enterrado en Oña ${ }^{56}$. El 13 de mayo de 1029 caía asesinado en León su hijo el conde García, el infant, y me parece lo más probable que su cuerpo fuera llevado por su séquito a $\mathrm{Oña}{ }^{57}$, del mismo modo que medio siglo más tarde los castellanos trasladarán desde Zamora los restos del rey Sancho o los leoneses llevarán los de Vermudo III desde el valle del Tamarón hasta León.

En octubre de 1035 moría Sancho el Mayor. Nuestras fuentes coinciden en establecer su sepultura en Oña ${ }^{58}$ y en asignar protagonismo en las exequias a su hijo Fernando. La crónica del Pseudo-Pedro, el testimonio leonés más cercano a los acontecimientos, señala su enterramiento en el monasterio y el papel destacado que le cupo a Fernando ${ }^{59}$. La Crónica Najerense recogió esa información, apuntando que el rey navarro morbo proprio hac uita decessit..., quem Ferdinandus apud Oniense monasterium honore debito sepeliuit ${ }^{60}$. La crónica incluida en el códice de Roda confirma esa sepultura, aunque no otorga protagonismo especial a Fernando, quizá debido a su propio laconismo o a alguna voluntad de minimizarlo ${ }^{61}$.

La referencia del Pseudo-Pedro a que el primogénito de Sancho III, García el de Nájera, se encontraba de peregrinación en Roma pudo llevar a pensar que

55 Conviene recordar cómo, siguiendo las instrucciones de su hermano Benito, el cuerpo de Escolástica fue depositado en la tumba que el fundador monástico tenía preparada para él (Dial., II, 34).

56 Sepultus apud Onie monasterium, quod fecerat (Najerense, III, 1 / III, 5).

57 Sobre el epitafio de Oña, MENÉNDEZ PIDAL: «Romanz del infant García», en Idea imperial de Carlos V, Madrid, 1971, 91ss. Tanto el Tudense como Jiménez de Rada establecen su entierro en San Juan Bautista de León, en donde se conserva un sarcófago a su nombre, pero la Primera Crónica General sostiene que fue enterrado en Oña, a donde lo llevó Sancho III, aunque recoge también la opinión de Rada (MenÉndez Pidal, R. y Catalán, D. eds.: Primera Crónica General de España, Madrid, 1977, II, $\mathrm{n}^{\circ}$ 788, p. 471). El sarcófago de León con su 1,30 m. de largo y su epitafio parecen muy acomodados a la leyenda del infant («Romanz», p. 90).

58 Las inscripciones funerarias onienses en BARREDA, I.: Oña y su real monasterio, 100 y s. Herrera Oria defiende el enterramiento de Sancho III en Oña.

59 Quem Fernandus apud Oniense cenobium magno cum honore, ut tantum patrem decebat, bumari fecit (Historia Silense, 76, p. 180, ed. PÉrez DE Urbel y RuIZ Zorrilla: Historia Silense, Madrid, 1959). Sobre la propuesta de nombre remito a ISLA, A.: Memoria, culto y monarquía hispánica entre los siglos $X$ y XII, caps. VII y VIII. El texto lo copia Lucas de Tui (Chronicon Mundi, IV, 46; ed., FALQUE, Turnholt, 2003).

60 Najerense, III, 3 / III, 11.

61 s.a. 1035. 3: Obiit in era TLXXIII. Sepultus est Onie monasterio (ed., LACARRA: «Textos navarros del códice de Roda», en E.E.M.C.A., I, p. 69). 
las exequias del rey navarro tuvieron algo de anormal, algo de decisión dolosa de Fernando frente a las voluntades de su padre y del resto de la familia. Quizá por ello la Crónica Najerense se vio impelida a sostener que García ya había retornado cuando tuvo lugar el entierro ${ }^{62}$.

Estas dudas han aflorado también en la historiografía. Pérez de Urbel señalaba que los hijos del rey navarro no se molestaron en trasladar el cuerpo de Sancho III a uno de los grandes santuarios, a San Millán, a San Juan de la Peña o a Leire, donde descansarían sus antepasados. Quizá había en esta opinión el eco de la leyenda sobre el juicio contra la esposa de Sancho, acusada injustamente de adulterio por su hijo García, según la mencionada fabulación ${ }^{63}$, que en alguna de sus versiones también implicaba en este calumnioso comportamiento a Fernando. Para Pérez de Urbel pudo ser Munia la que insistió en que Sancho III fuera enterrado en Oña junto a su padre el conde Sancho ${ }^{64}$.

En toda esta percepción anida la extrañeza sobre el lugar de sepultura del rey navarro. Quizá, como hemos visto, podía achacarse a un apoderamiento de la ceremonia por Fernando, valiéndose de la ausencia del primogénito o, como quería Pérez de Urbel, a la influencia de Munia. Tanto el Pseudo-Pedro como la Najerense destacan que Sancho III fue sepultado magno cum honore o bien honore debito, con lo que difícilmente es admisible algún descuido en sus honras fúnebres.

La herencia de Sancho el Mayor había otorgado territorios a todos sus hijos varones, incluido Ramiro. Ya sea en este diseño testamentario o a resultas de la victoria de los hermanos Fernando y García en el Tamarón sobre Vermudo III, los territorios orientales de Castilla recayeron en García, el de Nájera, quien se titulaba rey in Pampilonia, in Alaua et in Castella Uetula ${ }^{65}$. Algún documento oniense posterior al 1035 abunda en esta visión. En 1045 un presbítero donaba a Oña unas heredades en Bascuñuelos, no lejos de Traspaderne, concesión que señalaba que García era rey en Pamplona, en Álava y Castilla, mientras que Fernando, que figura en segundo lugar, lo era en León y en Burgos ${ }^{66}$. Al año siguiente son los propios reyes García y Estefanía los que realizan una donación al monasterio de una iglesia situada en Pancorbo ${ }^{67}$.

62 filio eius rege Garsia Romam redeunte, morbo proprio... (III, 3 / III, 11).

63 La leyenda tiene sus raíces en la «necesidad» de reforzar el prestigio de Ramiro, hijo natural de Sancho, profiliado y reconvertido como hijo de la reina. Puede verse, SÁnCHEZ CANDEIRA: Castilla y León en el siglo XI. Estudio del reinado de Fernando I, Madrid, 1999, 98ss.

64 Sancho III, el Mayor, 229s.

65 Una escritura emilianense del 1053 presenta a García como rey in Pampilona et in Nagera et in Alaba et in Castella Vetula usque ad fluvium qui vocitatur Aslanzone (San Millán, $\mathrm{n}^{\circ}$ 288). Opción diferente en LACARRA: «El lento predominio de Castilla», en Investigaciones de Historia navarra, Pamplona, 1983, 143s. Ya advertí de la diversidad en adjudicar el inicio de esos repartos en Realezas hispánicas del año mil, Sada-Coruña, 1999, p. 146.

66 Garcia rex in Pampilone, in Alaue, et Castelle, adque eius frater Ferdinandus rex, in Legione et in Uurgus $\left(O \tilde{n} a, \mathrm{n}^{\circ} 31\right)$.

67 Oñ, $\mathrm{n}^{\mathrm{O}} 32$. 
En realidad este expansionismo navarro hacia Álava y Castilla se advierte de manera difusa, puesto que los documentos que han dado pie a afirmar una manifestación abierta y rotunda de esta realidad, con intitulaciones en que diversos reyes se proclaman como tales sobre estos territorios, a menudo basándose en las referencias de Pérez de Urbel, son susceptibles de estar mal datados o de haber sufrido por parte de los copistas la amplificación de los títulos regios $^{68}$. De su reinado y en fecha posterior al 1017, pero anterior a la muerte del infant García, Sancho aparece en algunas escrituras con la titulación de rex sobre Álava y Castilla que convendría repasar con tiento ${ }^{69}$.

Esta política de expansionismo hacia Castilla, no obstante, puede advertirse en elementos menos rotundos, pero quizá más firmes. Así, en el matrimonio de Alfonso V con Urraca, la hermana de Sancho III, una unión, producida en 1023, que retornaba a las alianzas habituales entre León y Pamplona y que sólo tenía sentido frente a Castilla, en donde García cumplía los catorce años. También me parecen muy relevantes las presencias de los obispos de la sede de Valpuesta —en concreto Sancho_- y la alavesa — los obispos García y Munio- en el entorno de Sancho el Mayor $^{70}$. En algunos documentos emilianenses del período que se inicia en 1020 figura junto al rey navarro un obispo que puede ser García de Álava y un Sancho que debía regir Valpuesta; y en una escritura de 1028 consta el obispo Julián que ha de ser el de Oca ${ }^{71}$. Además, en un documento de Albelda de 1024 aparece en el entorno regio navarro el obispo Munio de Álava ${ }^{72}$. Desde

68 Los copistas daban a los monarcas el máximo de títulos que gozaron en su vida, por más que no correspondiera a la cronología del documento (ISLA, A.: Realezas hispánicas, 135s).

69 En realidad no hay muchos documentos entre 1017 y 1029 que muestren este expansionismo y que no puedan ser datados con posterioridad. Uno de ellos es San Millán, no 176 que puede ser del 1022. Allí se menciona a Sancho como rey en Castilla. Mas el documento está fechado en el 962 y puede ser de hasta 1034, siendo las fechas post-1029 las más verosímiles. En otra escritura (MARTÍn DuQUE: Documentación medieval de Leire (siglos IX a XII), Pamplona, 1983, $\mathrm{n}^{\circ}$ 22) aparece Sancho como rey in Pampilona et in Aragone et in Castella. Sin embargo, está mal datada y Pérez de Urbel la cree de 1022, pero su afirmación es discutible. Martín Duque basa en esta escritura el ejercicio de la potestas de Sancho el Mayor en tierras castellanas ( El reino de Pamplona» en La España cristiana de los siglos VIII al XI. Los núcleos pirenaicos: Navarra, Aragón, Cataluña, Madrid, 1999, 222). Por otra parte, ha revisado estos documentos de Leire y no parecen confirmar el temprano dominio de los territorios castellanos. Con anterioridad a 1029, Martínez Díez cree que sólo una de las varias escrituras emilianenses de Sancho III fechadas en 1014 sería auténtica («El monasterio de San Millán...», 42s).

Los documentos de San Juan de la Peña tienen también la titulación amplificada que no se corresponde a la data.

70 Sobre estos obispados castellanos, MARTínez DíEZ: «Los obispados de la Castilla condal hasta la consolidación del obispado de Oca en Burgos en el concilio de Husillos (1088)» en LÓPEZ SANTIDRIÁN, ed.: El factor religioso en la formación de Castilla, Burgos, 1984, 87-164.

71 San Millán, $\mathrm{n}^{\mathrm{o}} 171$ y $\mathrm{n}^{\mathrm{o}} 179 ; \mathrm{n}^{\mathrm{o}} 185$. Berganza y Pérez de Urbel ya advirtieron esta presencia de obispos y sacaron sus consecuencias (El obispado de Burgos, 221 y Sancho el Mayor, $115 \mathrm{ss})$.

72 UBieto: Cartulario de Albelda, Zaragoza, 1981, nº 31. 
esta perspectiva no es extraño que el nombre de Sancho III se haga presente en las calendaciones de algunos documentos castellanos junto a los de Alfonso $\mathrm{V}$ y el conde García: se estaba reconociendo su autoridad y revelando cierta indeterminación política en esas áreas.

Se ha interpretado todo ello como una tutela o un protectorado sobre el conde García, muy en la línea de su caracterización como infant, pero quizá no se trataba de una benéfica regencia. Tal actuación no era sino la continuidad de la tendencia que se había desarrollado en épocas anteriores. En buena medida, lo que nos transmite este comportamiento de Sancho es una voluntad previa y profunda de anexionarse estos territorios alaveses y del oriente burgalés. Precisamente por ello el conde Sancho había establecido Oña como monasterio de referencia condal en la zona.

De este modo, la sepultura en Oña del rey Sancho también venía a reforzar ese proyecto de expansión territorial. La sepultura de Sancho III creo que podría ser un elemento más para pensar que fue la división del reino la que asignó los territorios alaveses y orientales castellanos a García. Si ello fue así, García no obtuvo todos los réditos políticos posibles de esos acontecimientos. Su viaje fuera de la Península propició la intervención de Fernando, que asumió el papel protagonista y con su presencia mantuvo vivos los vínculos del condado con Oña. De ahí que lo recalcaran nuestras noticias.

No es probable que el lugar de sepultura de un monarca de cierta edad fuera seleccionado por Fernando. Ya hemos visto cómo estas graves decisiones no eran dejadas al albur del momento. Hemos citado cómo el cuerpo de García Fernández fue recuperado en su integridad, tras un tiempo de estar en tierras andalusíes y llevado a Cardeña. Lo más verosímil es pensar en una voluntad expresa por parte de Sancho el Mayor.

Algunos documentos onienses parecen mostrar una estrecha relación entre el monasterio y el rey Sancho. Se trataría de la donación de Santa María de las Muelas de fecha dudosa y la escritura de la introducción de la observancia cluniacense, supuestamente de 1033. Hay consenso entre los especialistas sobre la falsedad de ambas escrituras ${ }^{73}$. No obstante, es verosímil que una cierta transformación del monasterio tuviera lugar durante el reinado de Sancho. El conde Sancho había fundado un monasterio femenino o, al menos, dúplice, colocando al frente del mismo a su hija Tegridia como abadesa. Sin embargo, años más tarde encontramos en Oña al abad García ${ }^{74}$ y luego a Íñigo y a una comunidad masculina. Tal transformación quizá implicó erradicar un foco que remitía al

\footnotetext{
73 FACI, J.: «Sancho el Mayor de Navarra y el monasterio de San Salvador de Oña», en Hispania XXXVII (1977), 299-317.

74 Pérez de Urbel (Sancho el Mayor, 282) creyó que este García sería el encargado, junto a Poncio, de llevar la carta del rey Sancho a Oliba de Vic (cum Garcia fidelissimo vestro), alcanzando más tarde el obispado de Álava. Una vez más se apoyaba en L. Serrano (El obispado de Burgos, I, p. 258 nota). Sin embargo, dada la frecuencia del nombre García, todo ello es aventurado. Su tránsito del monasterio al obispado resulta más verosímil.
} 
pasado y colocar en su lugar a un personaje decididamente partidario del rey navarro y su familia. En absoluto tratamos de reivindicar una entrada de la normativa cluniacense en Oña, pero nos consta la presencia contemporánea de monjes hispanos en Cluny y solemos admitir, como trasfondo de todas las leyendas fundacionales relacionadas con Sancho III, la veracidad de la actividad de estos monjes y sus nexos con el monarca. También sabemos de la estancia en Cluny del obispo de Pamplona, quien quiso pasar en estricta vida monástica el último tramo de su vida ${ }^{75}$.

No tenemos datos que establezcan alguna luz en todo este interesante fenómeno, excepto el hecho, que no debe ser desdeñado, de cambios que afectaron a una comunidad que dejó de ser dúplice para convertirse en masculina. Es muy probable que Sancho tratara de generar en el monasterio un centro más acorde con las sugerencias que recibía del entorno monástico, tanto de los hispani residentes en Cluny, de la propia abadía de la Borgoña y del abad Odilón o de Oliba. Como hipótesis supondría un reforzamiento de las fórmulas benedictinas y la desaparición de otras tradiciones, más permisivas con la presencia femenina ${ }^{76}$.

No parece haber sido un cambio especialmente profundo, dadas las pautas que barruntamos a través del documento fundacional de Oña. Se trataba más de romper con el esquema de monasterios para las mujeres de la familia condal que había sido tradicional entre los descendientes de Fernán González, también como un diseño de vida para los miembros femeninos del grupo. Ya no será posible su posición al frente de unas comunidades que habían gozado de predicamento en el pasado.

La actuación de Sancho III se adecuaba a otros modelos monásticos, decididamente benedictinos y masculinos, que tenían un considerable prestigio en su presente como centros al cuidado del mantenimiento de la memoria de los difuntos. Son éstos los valores que le llevaron a alterar la tradición de enterramientos reales navarros y buscar un lugar en principio novedoso. Con él no sólo reivindicaba un espacio que había pretendido el reino navarro desde hacía tiempo, también solventaba sus inquietudes religiosas. Él mismo había participado en el cincelado de la comunidad a lo largo de los años previos a su muerte.

Con todo, los pasos innovadores de Sancho III son lentos. No cabe pensar en una irrupción de la liturgia y los usos romanos en general. Es conocida la

75 Los hispanos llamaban la atención en la abadía borgoñona por sus extravagancias litúrgicas (GLABER: Historiae, III, 12). Sigue siendo interesante el trabajo de BISHKO: «Fernando I and the Origins of the Leonese-Castilian Alliance with Cluny», en Studies in Medieval Spanish Frontier History, Londres, 1980, II). Sobre la relación, JoTSALDO: Vita Odilonis, I, 7, PL, CXLII, 902; Epistola ad Paternum abbatem y Ad domnum Garseam, PL, CXLII, 941 s y 942.

76 Puede no ser especialmente relevante, pero en Oña se hallaba algún códice de la Expositio de Smaragdo de Saint-Mihiel «según el antiguo catálogo de sus códices» (Millares, A.: Contribución al corpus de códices visigóticos, Madrid, 1931, 169). También Linage, que destaca la conservación de un fragmento (LINAGE: Los orígenes del monacato benedictino en la Península Ibérica, León, 1973, II, 801). 
réplica negativa de Oliba de Vic cuando, instado por Sancho III, escribe sobre el proyecto de matrimonio de Alfonso V y su hermana. Sin embargo, nos interesan los razonamientos del abad y obispo. Un personaje buen conocedor de la tradición eclesiástica franca e hispana y plenamente consciente de lo que sucedía en su entorno critica el mencionado diseño marital. Oliba, para dar solidez a su argumentación, construye una respuesta basándose en diversas fuentes. Acude primero a las Escrituras, apoyando en una serie de citas su opinión negativa, primero con textos veterotestamentarios y luego del Nuevo Testamento. En un segundo desarrollo utiliza el recurso a la tradición conciliar, a los exempla canonum. Mas, los cánones que cita son el cuarto del concilio de Lleida del 546, el 5 del II concilio de Toledo y el 12 del concilio de Agde del 50677. Es decir, el material canónico que Oliba presenta ante el rey Sancho para convencerle de su veredicto condenatorio procede no de un ámbito distante, sino de la vieja tradición de los concilios de época visigoda contenidos en la Hispana. Oliba no estaba dispuesto a traer a colación discutibles o desconocidos elementos para reprobar las uniones incestuosas; se remitía a un bagaje con el que los eclesiásticos navarros estaban plenamente familiarizados. Estos eclesiásticos podían cotejar los textos mencionados con los de sus bibliotecas y repasar las condenas a estas uniones. Sólo, como último elemento, Oliba añade una disposición que atribuye al papa Gregorio y que afirma dada en un concilio en Roma. Era presentada, pues, no como una mera decisión conciliar, sino que era reforzada con el prestigio papal. Mas no se trata de Gregorio Magno, como quizá quedaba difuso en su misiva, sino de Gregorio II y del concilio reunido en Roma el $721^{78}$. Es probable que tal añadido deba ser relacionado con el empleo de colecciones de la Hispana ya interpoladas con material franco; en realidad uno de los caracteres de estos repertorios es la introducción de elementos contrarios a las uniones entre parientes ${ }^{79}$. Estas colecciones con material hispano interpolado y con diversos añadidos tendrán —eso creo- un papel notable en las evoluciones religiosas que se anuncian.

77 El texto de la carta en JunYENT: Diplomatari i escrits literaris de l'abat i bisbe Oliba, Barcelona, 1992 , n ${ }^{\circ} 12$, pp. 327ss. Junyent señala el origen de las citas, aunque remite a la edición de Migne. En la edición de Martínez Díez y F. Rodríguez el canon 12 de Agde es el 61, revelando alguna manipulación de la colección que manejaba. Por cierto, Oliba de Vic utiliza los textos en el mismo orden en que aparecen en la Hispana sistemática, seleccionando simplemente los que convenían a su argumentación (ed. MARTínez DíEZ: La colección canónica bispana, Madrid, 1976, I, 2, 386s). Pone, así, de relieve el modo de trabajar y el material al alcance de Oliba.

78 En realidad, Oliba resume una serie de cánones (el 8 y el 9) del citado concilio y añade la referencia al séptimo grado (MANSI: Sacrorum conciliorum nova et amplissima collectio, Florencia, 1766, $\mathrm{XII}$, col. 263). El c. 8 dispone que si quis consobrinam duxerit in conjugium, anathema sit. Et responderunt omnes tertio: Anathema sit. El c. 9: Si quis de propria cognatione, vel quam cognatus habuit, duxerit uxorem, anathema sit. Et responderunt omnes tertio: Anathema sit. También maneja una edición interpolada del concilio de Agde en un sentido más preciso con respecto al matrimonio entre parientes.

79 Se trataría de pasos intermedios, previos a las colecciones pseudo-isidorianas (MARTÍNEZ DíEZ: La colección canónica hispana, I, 355ss). 
Este repertorio de Oliba revela con notable precisión las coordenadas religiosas de Sancho el Mayor y, muy probablemente, las de otros poderes en el Occidente peninsular. Sólo lenta, casi inadvertidamente, se incorporaban elementos que iban alterando el panorama tradicional. Lo interesante del caso es que en torno a Oña podemos señalar algunos de estos procesos que tienen que ver con la creación de panteones, con la religiosidad de la Redención y con los avatares de la benedictinización. En estas evoluciones se pone de manifiesto la continuidad de muchas políticas del conde Sancho durante el reinado de Sancho III, tanto las religiosas, como las estrategias políticas no sólo con respecto a al-Andalus, sino también con otros territorios cristianos. En realidad, mucho de la obra del rey navarro se encuentra anunciado en la del conde. 